\title{
Pilot evaluation of an online weight management programme
}

\author{
S. Cawley ${ }^{1}$, S. Farrell ${ }^{1}$, D.G. Byrne ${ }^{2}$, M.J. Turner ${ }^{3}$, B. Clune ${ }^{4}$ and D. McCartney ${ }^{1}$ \\ ${ }^{1}$ School of Biological Sciences and Environmental Sustainability and Health Institute (ESHI), Dublin Institute of \\ Technology, Kevin St., Dublin 8, Ireland, ${ }^{2}$ GEMS Directorate, St. James's Hospital, James's St., Dublin 8, Ireland, \\ ${ }^{3}$ UCD Centre for Human Reproduction, Coombe Women and Infants University Hospital, Cork St., Dublin 8, Ireland \\ and ${ }^{4}$ DIT Student Health Centre, Dublin Institute of Technology, Aungier Street, Dublin 8, Ireland
}

While tools such as the Healthy Eating Index (HEI) and the Mediterranean Diet Score (MDS) have been designed to appraise dietary quality, all of these incorporate nutrient intake indices in their scoring systems, necessitating the use of nutrient analysis software ${ }^{(1)}$. The Dietary Assessment Tool (DAT) is a practical, food-based index for the assessment of dietary quality which also generates individualised dietary advice for users. This prospective pilot intervention study aimed to establish whether completion of a six-week online programme using the DAT was associated with significant weight loss and waist circumference reduction.

Students and staff of a third level institution $(n=183)$ were recruited to the online weight management programme. Eighty-five respondents met the minimum inclusion criterion of logging on to the study website at least twice. Thirty-one participants completed the full six-week programme. All participants who completed the programme lost weight $(n=31)$. Mean weight loss in males $(4 \cdot 2 \mathrm{~kg})$ was greater than that in females $(1.9 \mathrm{~kg})(P=0.004)$.

Table 1. Changes in anthropometric status among those completing a six-week online weight loss programme $(n=31)$

\begin{tabular}{|c|c|c|c|c|c|c|c|}
\hline & & $n$ & & & & & $P$-value \\
\hline & & & Mean & SD & Mean & SD & \\
\hline Weight $(\mathrm{kg}$; mean (SD)) & Males & 18 & $94 \cdot 9$ & $7 \cdot 2$ & $90 \cdot 7$ & $7 \cdot 2$ & $<0.002$ \\
\hline & Females & 13 & $73 \cdot 3$ & 11.7 & $71 \cdot 4$ & 11.7 & $<0.001$ \\
\hline & Overall & 31 & $82 \cdot 3$ & $14 \cdot 7$ & $79 \cdot 5$ & 11.9 & $<0.001$ \\
\hline Body mass index $\left(\mathrm{kg} / \mathrm{m}^{2} ;\right.$ mean $\left.(\mathrm{SD})\right)$ & Males & 18 & $30 \cdot 1$ & $2 \cdot 8$ & $28 \cdot 8$ & $2 \cdot 9$ & $<0.001$ \\
\hline & Females & 13 & $26 \cdot 6$ & $3 \cdot 6$ & $26 \cdot 0$ & $3 \cdot 8$ & 0.001 \\
\hline & Overall & 31 & $28 \cdot 1$ & 3.7 & $27 \cdot 2$ & $3 \cdot 7$ & $<0.001$ \\
\hline Waist Circumference (cm; mean (SD)) & Males & 18 & $102 \cdot 4$ & $7 \cdot 1$ & $97 \cdot 0$ & .3 & $<0.001$ \\
\hline & Females & 13 & $86 \cdot 7$ & $9 \cdot 0$ & $83 \cdot 5$ & $9 \cdot 8$ & $<0.001$ \\
\hline & Overall & 31 & $93 \cdot 3$ & $11 \cdot 3$ & $89 \cdot 2$ & $10 \cdot 8$ & $<0.001$ \\
\hline Waist-Height Ratio (mean (SD)) & Males & 18 & 0.57 & $0 \cdot 04$ & 0.54 & $0 \cdot 04$ & $<0.001$ \\
\hline & Females & 13 & $0 \cdot 52$ & $0 \cdot 05$ & $0 \cdot 50$ & 0.06 & $<0.001$ \\
\hline & Overall & 31 & $0 \cdot 56$ & 0.06 & 0.52 & 0.06 & $<0.001$ \\
\hline
\end{tabular}

Despite high attrition rates, completion of this six-week online weight loss programme was associated with decreases in weight and waist circumference, especially in men.

1. Waijers PM, Feskens EJ, Ocké MC (2007) Br J Nutr 97, 219-31. 